\title{
Superficial Laser-Glazing of Sprayed Alumina Coatings for Anti-Corrosion Performance
}

\author{
Yrene Longa,* Takashi Yamashita* and Mikio Takemoto* \\ * Materials Science Laboratory, Aoyama Gakuin University
}

\begin{abstract}
The laser glazing of gas-flame sprayed alumina was attempted to produce a coating resistant to hot corrosion with insulation capability. Superficial laser glazing was achieved by scanning a carbon dioxide laser with a large beam diameter at low velocity over the sprayed alumina coating impregnated with silicone sealant. Successful laser-glazing could be achieved by controlling the temperature of the metallic substrate. The laser-glazed alumina exhibited high insulation capability and good resistance to hot corrosion by $\mathrm{Na}_{2} \mathrm{SO}_{4}-\mathrm{V}_{2} \mathrm{O}_{5}$ at $900^{\circ} \mathrm{C}$.
\end{abstract}

Key words: alumina, coating, laser glazing, hot corrosion

\section{Introduction}

The use of ceramics in land-based process plants is limited to small parts by their low fracture toughness and low thermal shock resistance, in spite of their excellent chemical stability. To introduce ceramic construction materials with the excellent anti-corrosion performance, advanced coating methodologies such as PVD and CVD have been attempted. However, thin ceramic layers such as TiN and $\mathrm{Al}_{2} \mathrm{O}_{3}$ deposited by these techniques are reported to suffer cracks and exfoliation in corrosive environments in the absence of externally applied stresses. ${ }^{1), 2)}$

Spraying of oxide ceramics such as yttriaand magnesia-stabilized zirconia, has produced thermal barriers and heat-resistant coatings for gas turbine engines. ${ }^{3) \sim 5}$ Although porous coatings may offer some limited resistance to hightemperature gaseous corrosion, at elevated temperatures they permit the infiltration of contaminants such as molten salts. Laser glazing of sprayed ceramics has been attemped to modify these sprayed porous coatings $\left.{ }^{()} \sim 12\right)$; however, only a very few successful cases have been reported. Nanbu, et al. ${ }^{13)}$ evaluated the mechanical properties of sprayed titania, and noted that the porous titania possessed adequate adherence to the substrate metal and did not suffer any crack below the allowable stress of the substrate metal. Because pores in the sprayed

\footnotetext{
* 6-16-1, Chitosedai, Setagaya-ku, Tokyo, 157 Japan
}

coating are detrimental for isolating the substrate metal from the aggressive environment, laser fusing of a thin deposit of the sprayed titania by an infrared laser was attempted to obtain a high quality ceramic coating. Successful results could not be obtained for the titania coating due to the extremely high susceptibility to cracking and exfoliation during and after laser-glazing.

This paper reports the superficial laser-glazing by a carbon dioxide laser of sprayed alumina which yields both insulation capability and corrosion resistance. The new "superficial glazing" technique $^{14)}$ prevents severe cracking of the ceramic coating and results in improved anticorrosion performance for the glazed alumina.

\section{Test Specimens and Laser-Glazing Method} Alumina powder (Metco 105NS : $98.5 \% \mathrm{Al}_{2} \mathrm{O}_{3}$, $1 \% \mathrm{SiO}_{2}$ and $0.5 \%$ other oxides) was gas-flame sprayed onto a blasted AISI 304 steel of $100^{L} \times$ $100^{W} \times 5^{t} \mathrm{~mm}$, using an oxy-acetylene torch and a Metco gun 5P. The thickness of the deposited alumina was controlled to $200-250 \mu \mathrm{m}$. Two types of laser-glazing methods were applied: (a) the scanning beam method and (b) the overlapping single scanning beam method. Both methods were able to treat extensive areas; however, there were characteristic differences in their laser irradiation conditions which affected the resulting laser-glazed surface.

In the scanning beam method (Fig. 1-a) oscillating beam equipment was used. A band of 


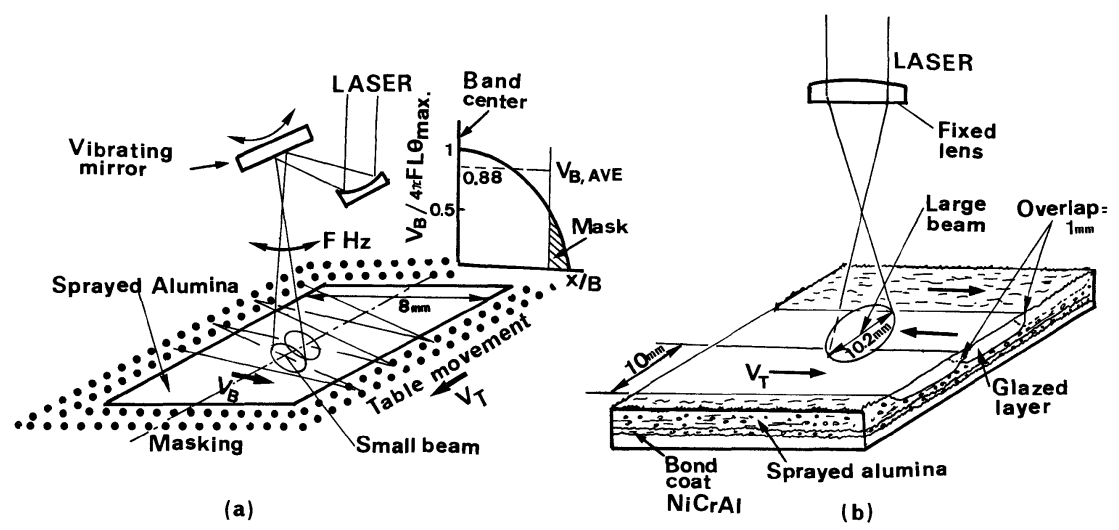

Fig. 1 Schematic illustration of the laser glazing methods employed: (a) scanning beam and (b) overlapping of single scans.

$8 \mathrm{~mm}$ width was melted during a single table movement. As the laser beam was oscillated by the vibrating mirror driven by a sine-wave potentiometer, the oscillating beam velocity $V_{\mathrm{B}}$, expressed by Eq. (1), drastically changed across

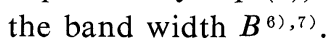

$$
\begin{aligned}
V_{B}= & 4 \pi F \theta_{\max } L \cos (2 \pi F \theta)=4 \pi F \theta_{\max } L \\
& \times\left\{\sin ^{-1}(x / B)\right\}
\end{aligned}
$$

where $\theta_{\max }$ is the maximum vibrating angle of the mirror $\left(9 \times 10^{-4} \mathrm{rad}\right)$ at a frequency $F, L$ is the distance between the lens and the specimen (focal distance $=304.8 \mathrm{~mm}+$ defocus) and $x / B$ is a normalized distance. Laser irradiation was done in the range of $x / B<0.8$ to avoid extremely high irradiation energies at the band edges. An average beam velocity, $V_{B \text {,avg. }}$ is estimated to be $0.88 \times 4 \pi F \theta_{\max } L$. As the quality of the alumina fused by this method depends to a great extent on the specific energy $E$ and the beam overlap number $N$, these two parameters defined by Eqs. (2) and (3) were mainly used to characterize the laser-irradiation:

$$
\begin{aligned}
& \text { Specific energy } E=P_{d} \times t_{d} \\
& \text { Overlap number } N=2 D F / V_{T}
\end{aligned}
$$

where $P_{d}$ is the power density $=P /\left(\pi D^{2} / 4\right), t_{d}$ the dwell or irradition time given by Eq. (4), $D$ the beam diameter and $V_{T}$ the table velocity:

$$
t_{d}=D / \sqrt{V_{T}{ }^{2}+V_{B}{ }^{2} \text {,avg. }}
$$

As the minimum frequency of the vibrating mirror was $4.5 \mathrm{~Hz}$, the dwell time was about $10^{-3}$ seconds for a small beam diameter of 0.49 $\mathrm{mm}$ at a defocus distance of $4.8 \mathrm{~mm}$.

According to the second method, the overlapping of single scanning passes (Fig. 1-b), a large diameter laser beam of $10.2 \mathrm{~mm}$ (defocus distance $=100 \mathrm{~mm}$ for a focal distance $=304.8$ $\mathrm{mm}$ ) was scanned in one direction at a low scanning velocity $(0.02$ to $1.50 \mathrm{~m} / \mathrm{s})$. The entire surface was glazed by overlapping the melted bands by $1 \mathrm{~mm}$. The dwell time, which was in the range of $5-10 \mathrm{~s}$, is defined by Eq. (5):

$$
t_{d}=D / V_{T}
$$

By this method, the following additional countermeasures to prevent the cracking and exfoliation of laser fused alumina were attemped:

(1) sealing of the sprayed alumina with a silico-organic sealant

(2) deposition of a bond coat of $\mathrm{NiCrAl}$

(3) slow cooling of the coating

For the application of the silicone, Shin-Etsu silicone KR-251 was disolved in toluene $(50 \%$ vol.) and the alumina coatings were painted with this solution so that the resultant amount of silicone sealant coat was $\sim 6 \mathrm{mg} / \mathrm{cm}^{2}$. The silico-organic sealer prevents cracking when glazing because it acts as a tightener, filling the pores in the sprayed alumina by capillary action. To improve the adhesion of the alumina coating, the $\mathrm{NiCrAl}(76.5 \mathrm{wt} \% \mathrm{Ni}, 19.5 \mathrm{Cr}, 4.0 \mathrm{Al})$ bond coating of $200 \pm 30 \mu \mathrm{m}$ in thickness was sprayed using gas flame spraying system, the same method used for the alumina deposition. When sprayed, $\mathrm{NiCrAl}$ alloy forms oxides ${ }^{14)}$ as $\mathrm{Al}_{2} \mathrm{O}_{3}$ and $\mathrm{Cr}_{2} \mathrm{O}_{3}$ which provide the coating with near ceramic properties. The formation of chemical bonds ( $\sim 100$ times stronger than physical forces) between the ceramic and the bond coat is possible, and thermal stresses induced by large differences in the coefficients of expansion between ceramic $\left(\sim 8.10^{-8} / \mathbf{K}\right)$ and substrate $\left(\sim 14.10^{-6} / \mathrm{K}\right)$ are attenuated with an intermediate 


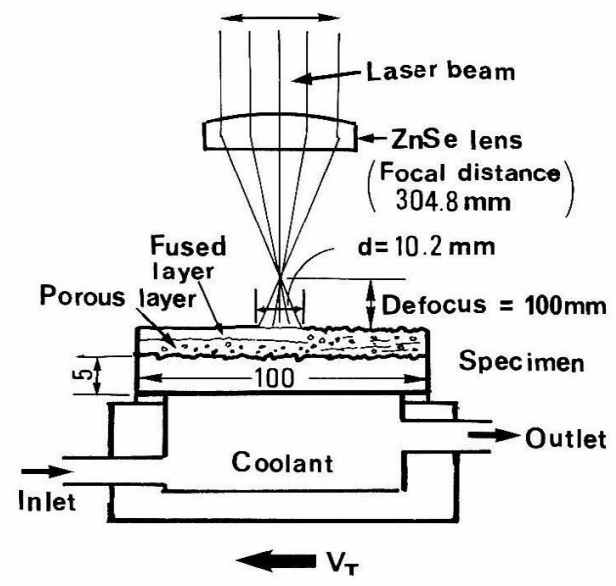

Fig. 2 Setup used in the overlapping of the single scans method.

layer of oxide and metal mixture. ${ }^{15)} \mathrm{NiCrAl}$ bond coat also moderates the temperature gradient between the ceramic and the substrate when glazing. To accomplish the controlled cooling, which also diminishes the specimen thermal expansion, special equipment shown in Fig. 2 was used, so that the opposite side of the substrate was cooled by a flowing coolant which was at a constant temperature of $15^{\circ} \mathrm{C}$.

\section{Results and Discussion}

Laser glazing of sprayed alumina by the scanning beam method

The scanning beam method was not completely successful, but the results are introduced here because the data suggest an important direction for laser glazing.

The laser beam with a doughnut-type multimode $\left(\mathrm{TEM}_{01}\right)$ power profile, ranging from 50 to $250 \mathrm{~W}$, was irradiated on the as-sprayed alumina without the NiCrAl bond coating. The numerically controlled working table was driven at velocities of $0.05-0.20 \mathrm{~m} / \mathrm{min}$ perpendicular to the oscillating beam. All operations were made without the use of an assist or shield gas. The laser power required for fusing the alumina was not as high as that required for fusing metals because of the high infrared laser absorption of the alumina.

Because the sprayed alumina suffered severe cracking and exfoliation under any laser irradiation, it was impregnated with the silicone sealant prior to the laser irradiation. The surface of the silicon-sealed alumina was then uniformly glazed using the irradiation conditions of region $B$ in Fig. 3. However, the glazed coating

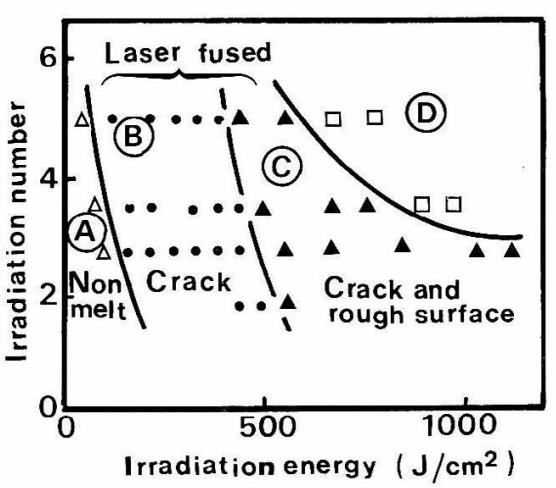

Fig. 3 Laser irradiation conditions set for the superficial glazing of the sprayed alumina using the scanning beam method.

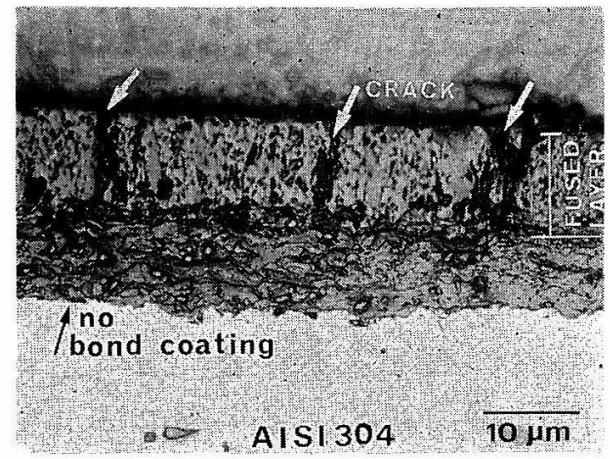

Fig. 4 Transverse section of the alumina glazed by the scanning beam method. No bond coating or cooling was used in this case.

suffered vertical cracks just at the beam overlap area (Fig. 4). A few pores (bubbles) was observed in the laser fused layer, but no vertical cracks were observed in the porous (non-fused) layer. Experimental data obtained by the scanning beam method indicated that (1) gas bubbles could not float out from the fused pool because of the high viscosity of the fused alumina and the short dwell time, and (2) cracks are likely to occ In when the alumina suffers repeated rapid heating and cooling at the beam overlap zone. A relatively long dwell time was required to permit the gas bubbles to escape and a special technique was necessary to prevent cracking, but the appropriate conditions could not be obtained by the scanning beam method due to the high velocity of the oscillating beam.

Laser-glazing of sprayed alumina by the overlapping of single scans

To achieve a long dwell time, a laser beam of large diameter $(10.2 \mathrm{~mm}$ for a defocus distance $=100 \mathrm{~mm}$ ) was scanned in one direction at 
low velocity. The laser power was varied from 500 to $1600 \mathrm{~W}$ and a band of $10 \mathrm{~mm}$ width was melted in a single scan. The dwell time using this method was set between 0.5 and 10 seconds, about 1,000 to 10,000 times higher than that for the scanning beam method. Figure 5 shows the favorable laser irradiation conditions, expressed as a function of laser power density and dwell time $(P=400-1000 \mathrm{~W} ; D t=0.5-10 \mathrm{~s})$. When the alumina coating was glazed under these conditions, the region fused by the following laser beam (second pass) had the tendency to exfoliate when it was laser irradiated without any additional countermeasure, as shown in the schematic illustration of Fig. 6-A; because of presence of pores in the alumina, the weak bonding strength alumina/SUS 304, and the mismatch in the especimen (alumina/metallic substraste) thermal expansion. Therefore, the three previously specified countermeasures were attempted: use of the silico-organic sealant, use of the NiCrAl bond coating, and slow cooling of the substrate.

As it was explained, the silico-organic paint seals the pores in the coating facilitating the glazing without the formation of bubles which conduces to cracking, while the bond coat increases the adhesion of the ceramic coating. Extensive research suggests that there is an optimum substrate temperature (heat flux) which can prevent both exfoliation and cracking. Similar studies made by the authors on zirconia (non-published) indicate that for substrate temperatures over $400^{\circ} \mathrm{C}$ during the Laser-glazing,

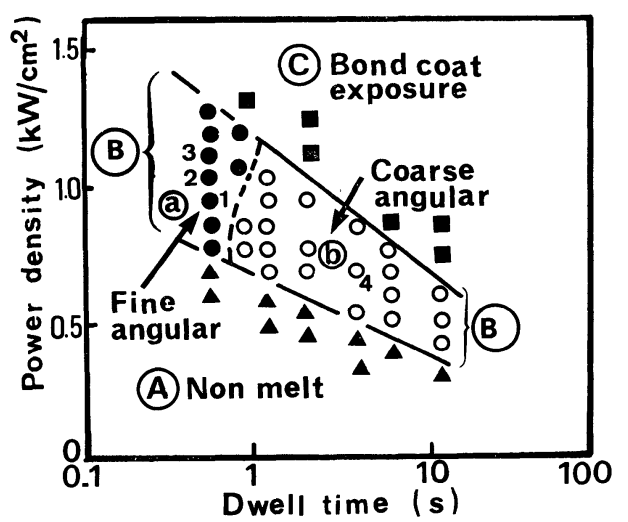

Fig. 5 Laser irradiation conditions for the sprayed alumina coatings on a substrate (opposite surface) cooled at $15^{\circ} \mathrm{C}$. Region B corresponds to the favorable conditions from which specimens 1 to 4 where submitted to insulation capability tests. the ceramic coating tends to exfoliate. For alumina, coolant temperatures ranging from -10 to $25^{\circ} \mathrm{C}$ where experimented, but the control of the substrate temperature at $\sim 200^{\circ} \mathrm{C}$ by flowing a coolant at $15^{\circ} \mathrm{C}$ was effective for preventing cracks in the alumina coating. The substrate temperature varied from 199 to $200^{\circ} \mathrm{C}$ during the laser-glazing. However, when the temperature of the coolant was under $10^{\circ} \mathrm{C}$ (excess cooling), the alumina coating glazed by the previous scan (first pass) exfoliated (Fig. 6-B). The exfoliation of the alumina fused by the first beam pass was caused by compressive buckling, resulting from rapid thermal expansion in the following scan (second pass). Also, under $10^{\circ} \mathrm{C}$ the alumina coating could be at the dew point temperature for the water-vapor. If water is condensed on the alumina surface, cracks and exfoliation woulp occur due to the impact between the laser beam and water molecules. Exfoliation was not observed when the coolant contacting the bottom surface of the substrate was controlled at about $15^{\circ} \mathrm{C}$ (Fig. 6-C); this optimum temperature seems to depend on the thickness of the alumina and the substrate, the laser power, and also the ambient temperature.

Appropriate laser irradiation conditions of Fig. 5 correspond to the alumina affected by all these countermeasures. Region B, where homogeneous glazing was obtained, provided microstructures which could be classified into two types: (a) a fine angular structure of a few micrometers dimension and (b) a coarse angular
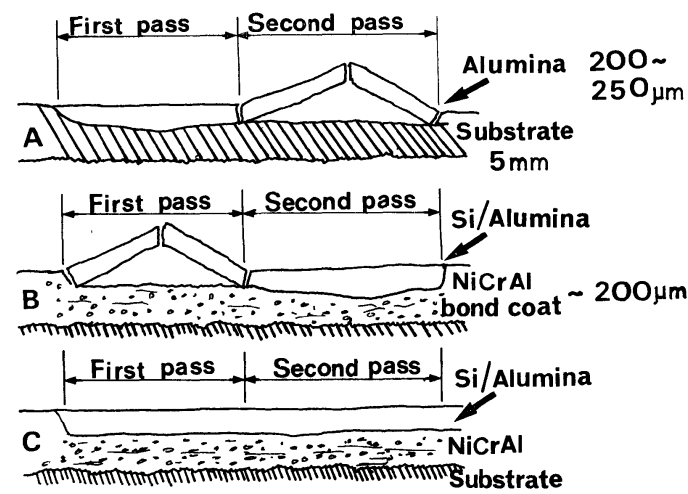

Fig. 6 Schematic glazing process of Alumina by overlapping of single scans. First and second passes corresponding to the respective scans: (A) Without any countermeasure. (B) With all countermeasures, coolant at $10^{\circ} \mathrm{C}$ (excess of cooling). (C) No exfoliation after using all countermeasures, coolant at $15^{\circ} \mathrm{C}$. 
structure of 10 micrometers size. These morphologies are shown in Fig. 7. Zone (b), characterized by long dwell times and high laser power densities, produced the coarse angular structure. Figure 8 shows the transverse section of the alumina glazed by this method. Although some pores exist in the glazed layer, they are expected to be mostly isolated.

X-ray diffraction (XRD) showed that the assprayed alumina was alpha alumina of corundum structure, and gamma (cubic) alumina; however, upon the laser glazing the gamma
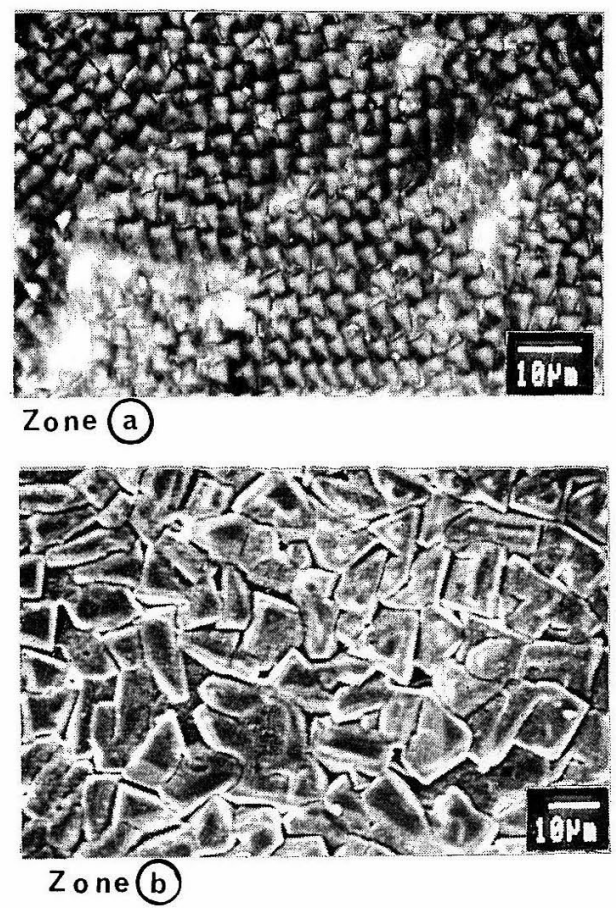

Fig. 7 SEM micrographs of the superficial glazed alumina. (a) Fine angular and (b) coarse angular structures, both corresponding to region B in Fig. 6.

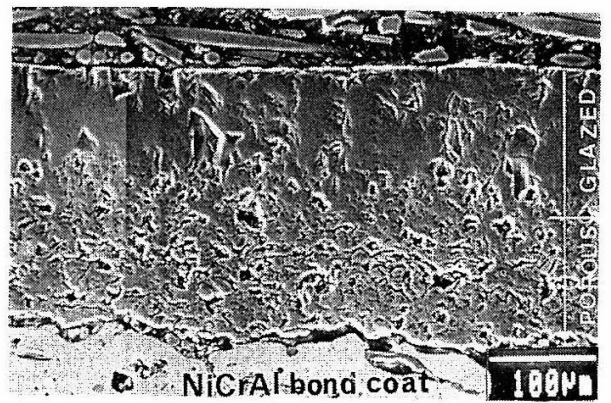

Fig. 8 Morphology of the transverse section of the superficially glazed alumina employing the overlapping single scans method. transformed to alpha alumina. No silicone compound could be detected by XRD although by means of EMPA it was observed that the glazed alumina top surface was rich in silicone and, in some cases, silicone penetrated the alumina coating more than $160 \mu \mathrm{m}$ in depth. The Vickers hardness of the as-sprayed alumina was in the range of 500 to 900 , and that of laser-glazed alumina reached 1050 to 1850 . This increase of hardness suggests that the porous coating became dense alpha alumina.

Evaluation of the insulating capability and anticorrosion performance

1. Insulating Capability

According to the Japanese Industrial Standard (JIS H 8666), the high-voltage spark method and ferroxyl method (color change determination) are recommended for examining pores in sprayed ceramics (alumina and zirconia). These methods are not adequate for evaluating the insulating capability of laser-glazed alumina because any pores existing in the glazed layer are assumed to be too small to be detected. Therefore the following method was used : the current passing through glazed specimens coupled to a Pt-electrode immersed in a solution of $4 \mathrm{~N} \mathrm{H}_{2} \mathrm{SO}_{4}$ $+0.4 \mathrm{~N} \mathrm{NaCl}$ at $40^{\circ} \mathrm{C}$ was measured using a zero-resistance galvanometer. To isolate the glazed area during testing, the surface of the specimen outside the exposure area of $15 \times 15$ $\mathrm{mm}$ was covered by silicone rubber. The AISI 304 substrate showed a typical active-passivetranspassive behavior in this solution. The corrosion and Flade potentials of AISI 304 were

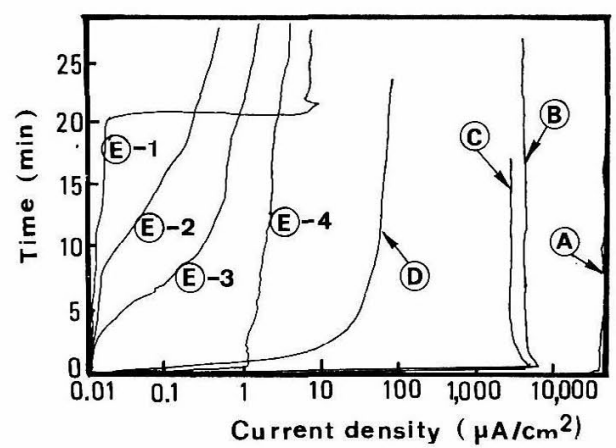

Fig. 9 Insulation capability tests. Curves showing the change of current density as a function of time. (A) Substrate, (B) gas-flame-sprayed alumina, (C) plasma-sprayed alumina in air, (D) silicone-sealed plasma-sprayed alumina, (E) laser-glazed alumina; E 1-3: fine structured, E-4: coarse structured alumina. 
-0.37 and -0.08 volt (vs. S.C.E.), respectively. AISI 304 showed passivation up to +1.0 volt and a passivation current density of $50 \mu \mathrm{A} / \mathrm{cm}^{2}$. The anodic current density of AISI 304 at the electrode potential of -0.18 volt was $100 \mathrm{~mA} /$ $\mathrm{cm}^{2}$. Figure 9 shows the change in the current density for five specimens tested: substrate (curve A), gas-flame-sprayed alumina (curve B), plasma-sprayed alumina in air (curve C), silicone-sealed plasma-sprayed alumina (D) and laser-glazed (gas-flame-sprayed) alumina (curves E 1 to E 4). Silicone-sealed plasma-sprayed alumina (curve D) shows a low current density $\left(\sim 50 \mu \mathrm{A} / \mathrm{cm}^{2}\right)$ which is similar to the passivation current density for AISI 304 steel.

While pure alpha alumina itself is an electrical insulating material, most of the laser-glazed alumina coatings showed a lower current density than the passivation value for the substrate. Specimen E-4 with coarse structure exhibited an especially high current density probably due to the easicr (comparcd to the fine structured) infiltration of the corrodant through the grain boundary grooves. In general, specimens E-1, E-2 and E-3 with fine-grained structure showed high insulation capability $\left(10^{4}-10^{5} \mu \mathrm{A} / \mathrm{cm}^{2}\right.$ lower than the sprayed alumina) although sometimes they exhibited an abrupt change in the current density as shown by E- 1 . This change in the current may be explained by the aleatory presence of isolated pores existing in the ceramic coating which allow the impregnation by the corrosive agent. Moreover, metallic particles derived from the bond coat may be introduced into the ceramic coating during the spraying, producing a current flow when reacting with the severe corrodant. Similar results were obtained in $5 \mathrm{~N} \mathrm{NaCl}$ solution.

2. Corrosion resistance of glazed alumina

Alumina is well known for its resistance to different kinds of wet and dry agressive environments; its corrosion behavior in high temperature environments has been studied. ${ }^{18), 17)}$ The corrosion resistance of the as-sprayed and glazed alumina coatings was evaluated by submitting the specimens to the molten salt corrosion test (lightly modified) recommended by the Japan Society for the Promotion of Science (Committee 123). Specimens coated with $5 \mathrm{mg} /$ $\mathrm{cm}^{2}$ of $80 \mathrm{wt} \% \mathrm{Na}_{2} \mathrm{SO}_{4}-\mathrm{V}_{2} \mathrm{O}_{5}$ salt were exposed at $900^{\circ} \mathrm{C}$ in stagnant air for $3 \mathrm{~h}$. Figure 10 shows the transverse section of the as-sprayed alumina after the molten salt test. The porous alumina exfoliated from the $\mathrm{NiCrAl}$ bond coat

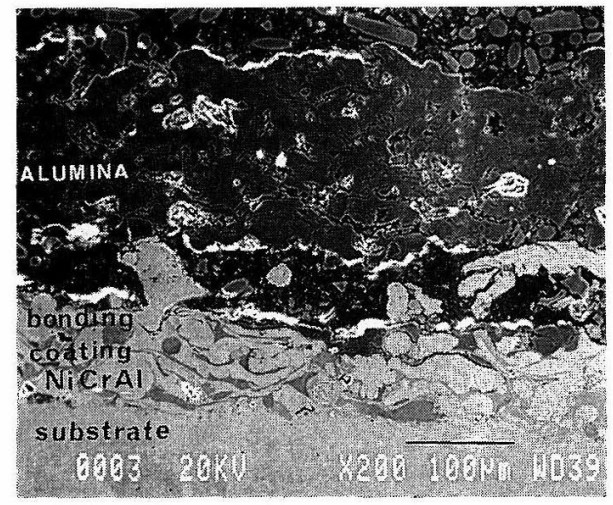

Fig. 10 Scanning electron micrographs of the assprayed alumina after 3 hours of molten salt test.

allowing the impregnation of the molten salt. Similar results were also obtained for silicone sealed-sprayed alumina. Although XRD patterns of the exfoliated alumina coating and the bond coat NiCrAl after the test did not indicate the formation of any corrosion product, degradation of the alumina is suggested by its change in color (blackish) and exfoliation.

Previous studies of the behavior of $\mathrm{Al}_{2} \mathrm{O}_{3}$ in $\mathrm{Na}_{2} \mathrm{SO}_{4}$ and/or $\mathrm{V}_{2} \mathrm{O}_{5}$ show that this behavior depends on the acidic and basic solubilities in the melt. ${ }^{16) \sim 18)}$ In the presence of pure $\mathrm{Na}_{2} \mathrm{SO}_{4}$, alumina appears to have some region of relative stability. In this research, due to the acidic nature of the melt $\left(80 \mathrm{wt} \% \mathrm{Na}_{2} \mathrm{SO}_{4}-\mathrm{V}_{2} \mathrm{O}_{5}\right)$, the acidic dissolution of the alumina to form sulfate and vanadate compounds should take place, according to: ${ }^{16)}$

$$
\begin{aligned}
& \mathrm{Al}_{2} \mathrm{O}_{3}=2 \mathrm{Al}^{3+}+3 \mathrm{O}^{2-} \\
& \mathrm{Al}_{2} \mathrm{O}_{3}+2 \mathrm{NaVO}_{3}=2 \mathrm{AlVO}_{4}+\mathrm{Na}_{2} \mathrm{O}
\end{aligned}
$$

Conversely, laser-glazed alumina did not show permeability to the molten salt and offered good corrosion resistance. As shown in Fig. 11a, the surface morphology of the fine-structure glazed alumina became smoother after the attack. Metallographic observations of the transverse section (Fig. 11-b) did not show evidence of penetration. This suggests that dense and fine-structured alumina coatings possess good resistance against the severe molten salt attack.

The morphology of the coarse-structure glazed alumina after the molten salt test is illustrated in Fig. 12. The surface structure also became smooth (Fig. 12-a), and some coarse grains near the surface fell out because of molten salt impregnation along grain boundaries, while the 

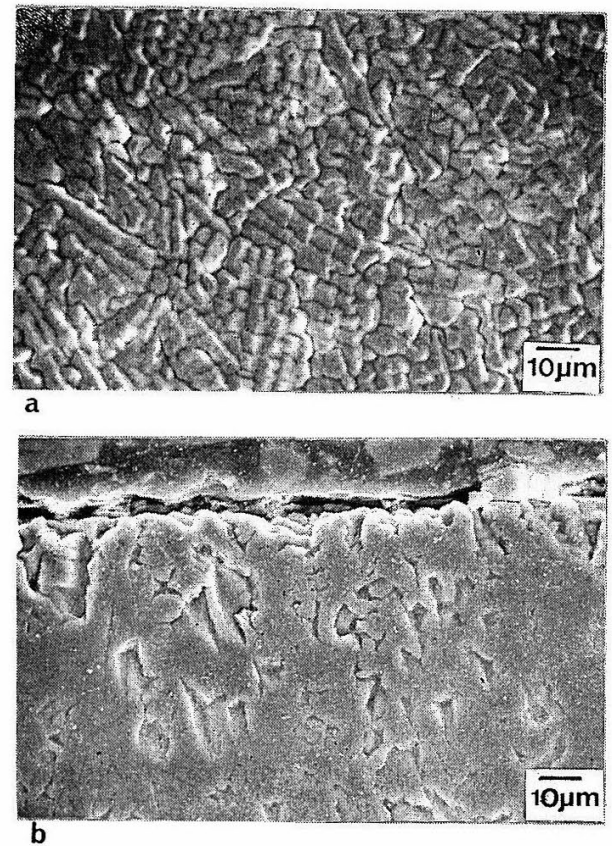

Fig. 11 SEM micrographs of the fine structured glazed alumina after molten salt test. (a) Surface morphology and (b) cross-section.

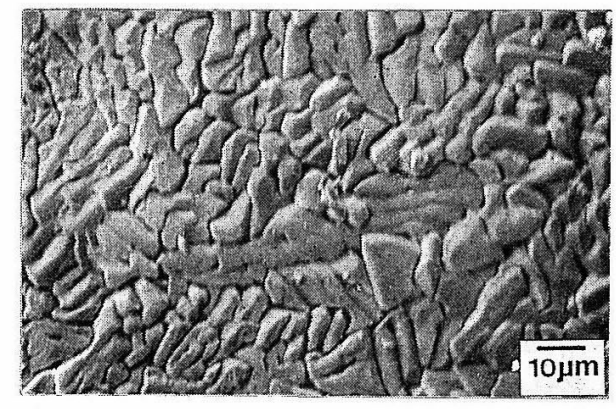

a

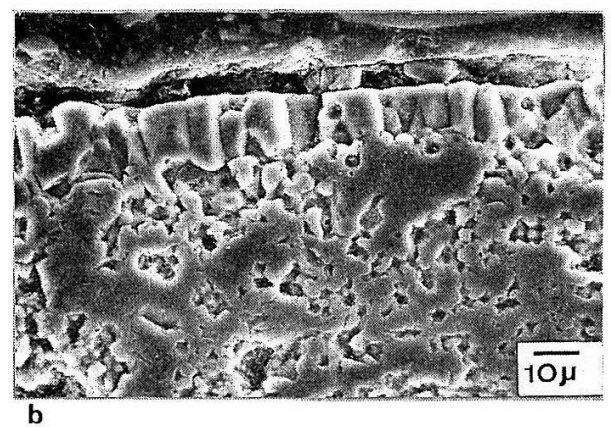

Fig. 12 SEM micrographs of coarse structured glazed alumina after molten salt test. (a) Surface morphology and (b) cross-section.

presence of some pores was observed in the transverse section of the specimen (Fig. 12-b). The grain boundary grooves (gap) of this coarse

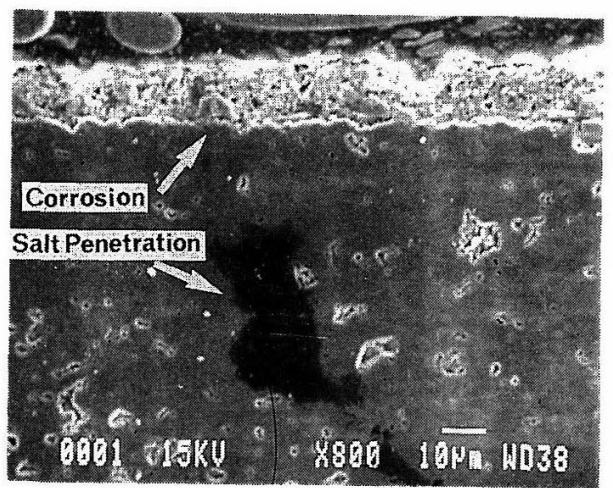

Fig. 13 Sintered alumina after 3 hours of molten salt corrosion test. Penetration of the molten salt into the alumina led to coating degradation.

coating are larger than those of the fine-structured one; thus the degradation seems to progress slowly. For comparison, a commercial alumina plate ( $95 \mathrm{wt} \%$ purity) produced by sintering was submitted to the same trials. SEM observations indicated severe corrosion of the surface (not observed in the glazed alumina) and EMPA showed the penetration of the molten salt into the alumina (Fig. 13), facilitated by its porous structure. XRD patterns of the corroded specimen also showed only $\mathrm{Al}_{2} \mathrm{O}_{3}$.

\section{Conclusions}

The superficial glazing of a gas-flame spraycd alumina can be achieved by irradiating a $\mathrm{CO}_{2}$ laser at extremely high dwell times (5-10 seconds), and by taking three special countermeasures to prevent cracking: the impregnation of a silico-organic sealant, the deposition of a NiCrAl bond coat and the control of the temperature of the metallic substrate. These countermeasures were effective in preventing both cracking and exfoliation of the glazed alumina. The laser-glazing produced two types of alumina, with coarse- and fine-grained structure. The latter demonstrated an excellent electrical insulation capability and superior corrosion resistance at high temperatures $\left(900^{\circ} \mathrm{C}\right)$ in presence of a $\mathrm{Na}_{2} \mathrm{SO}_{4}-\mathrm{V}_{2} \mathrm{O}_{5}$ deposit.

(Received December 20, 1991)

\section{References}

1) E. Endo \& K. Sugimoto: J. Japan Inst. Metals, 55, 957 (1991).

2) K. Takizawa, M. Fukushima \& H. Imai: Proc. Annual Meeting of $J$. Soc. Chem. Eng.. 225 (1990). 
3) R. Sivakumar \& B. L. Mordike: Surface Eng., 4, 127 (1988).

4) D. J. Wortman, B. A. Nagaraj \& E. C. Duderstadt: Mat. Soc. Eng., A 120, 433 (1989).

5) Y. Kojima, M. Fukushima \& K. Arimatsu: Rust Prevention and Control, 34, 113 (1990).

6) M. Takemoto, M. Tobari \& T. Shinohara: Proc. of 6th Asian Pacific Corrosion Control Conf., Singapore, p. C94 (1989).

7) M. Takemøto, M. Kumagai \& M. Yoshihara: ibid., p. C83.

8) M. Takemoto: in "High Power Lasers" Edited by A. Niku-Lari and B. L. Mordike, Pergamon Press, p. 75 (1988).

9) Y. Enami \& M. Takemoto: J. Japanese Spraying Soc., 26, H 1131 (1988).

10) N. Iwamoto, N. Umesaki \& S. Sendo: Advances in Thermal Spraying, Welding Inst. of Canada, Pergamon Press, p. 563 (1986).

11) A. Adamski \& R. McPherson: ibid., p. 555.
12) H. Havrda, K. Volenik, J. Wagner \& P. Mraz: ibid., p. 569.

13) T. Nanbu, Y. Enami, Y. Hayashi \& M. Takemoto: National Thermal Spray Conf., Pittsburgh, USA. May, 1991 (in press).

14) Y. Longa \& M. Takemoto: Proc. of 7th Asian Pacific Corrosion Control Conf., Beijing, China, p. 64 (1991).

15) P. E. Chandler \& M. B. C. Quigley: Advances in Thermal Spraying, Proc. 11th International Thermal Spraying Conference, Montreal, Canada, Pergamon Press, p. 29, (1986).

16) Y.S. Hwang \& R. A. Rapp: Corrosion., 45, 933 (1989).

17) P. D. Jose, D. K. Gupta \& R. A. Rapp: $J$. Electrochem. Soc., 133, 735 (1985).

18) J. A. Goebel, F. S. Pettit \& G. W. Goward: Met. Trans., 4, 261 (1973). 